\title{
Simultaneous Anaerobic Transformation of
}

\section{Tetrachoroethene and Carbon Tetrachloride in a Continuous \\ Flow Column}

Azizian F. Mohammad ${ }^{\mathrm{a}}$ and Lewis Semprini ${ }^{\mathrm{a}}$

${ }^{\mathrm{a}}$ School of Chemical, Biological and Environmental Engineering, 102 Gleeson Hall Oregon

State University, Corvallis, Oregon, 97331, United States

Author Information

Corresponding Author

Mohammad F. Azizian, 102 Gleeson Hall, Oregon State University Corvallis, OR 97331, Tel: 541-737-4492,mohammad.azizian@oregonstate.edu

\section{Author Contributions}

The manuscript was written through contributions both authors. Both authors have given approval to the final version of the manuscript.

\begin{abstract}
Tetrachloroethene (PCE) and carbon tetrachloride (CT) were simultaneously transformed in a packed column that was bioaugmented with the Evanite culture (EV). The data presented here have been obtained over a period of 1930 days. Initially the column was continuously fed synthetic groundwater with PCE $(0.1 \mathrm{mM})$, sulfate $\left(\mathrm{SO}_{4}{ }^{2-}\right)(0.2 \mathrm{mM})$ and formate $(2.1 \mathrm{mM})$ or lactate $(1.1 \mathrm{mM})$, but not CT. In these early stages of the study the effluent $\mathrm{H}_{2}$ concentrations ranged from 7 to $19 \mathrm{nM}$, and PCE was transformed to ethene (ETH) (81 to 85\%) and vinyl
\end{abstract}


chloride (VC) (11 to $17 \%$ ), and $\mathrm{SO}_{4}{ }^{2-}$ was completely reduced when using either lactate or formate as electron donors. $\mathrm{SO}_{4}{ }^{2-}$ reduction occurred concurrently with cis-DCE and VC dehalogenation. Formate was a more effective substrate for promoting dehalogenation based on electron donor utilization efficiency. Simultaneous PCE and CT tests found CT (0.015 mM) was completely transformed with $20 \%$ observed as chloroform (CF) and trace amounts of chloromethane $(\mathrm{CM})$ and dichlormethane $(\mathrm{DCM})$, but no methane $\left(\mathrm{CH}_{4}\right)$ or carbon disulfide $\left(\mathrm{CS}_{2}\right)$. PCE transformation to ETH improved with CT addition in response to increases in $\mathrm{H}_{2}$ concentrations to $160 \mathrm{nM}$ that resulted from acetate formation being inhibited by either CT or CF. Lactate fermentation was negatively impacted after CT transformation tests, with propionate accumulating, $\mathrm{H}_{2}$ concentrations being reduced to below $1 \mathrm{nM}$. Under these conditions both $\mathrm{SO}_{4}{ }^{2-}$ reduction and dehalogenation were negatively impacted, with sulfate reduction not occurring and PCE being transformed to cis-dichloroethene (c-DCE) (52\%) and VC (41\%). Upon switching to formate, $\mathrm{H}_{2}$ concentrations increasing to $40 \mathrm{nM}$, and complete $\mathrm{SO}_{4}{ }^{2-}$ reduction was achieved, while PCE was transformed to ETH (98\%) and VC (1\%), with no acetate detected. Throughout the study PCE dehalogenation to ethene was positively correlated with the effluent $\mathrm{H}_{2}$ concentrations.

\section{Keywords}

Tertachloroethene, carbon tetrachloride, bioaugmentation, fermentation, lactate, formate, hydrogen

\section{Corresponding Author}

${ }^{\ddagger}$ Mohammad Azizian, 102 Gleeson Hall, Oregon State University Corvallis, OR 97331, Tel: 541737-4492,mohammad.azizian@oregonstate.edu 


\section{Introduction}

Release of chlorinated aliphatic hydrocarbons (CAHs) into groundwater is a widespread environmental problem since they are known or suspected carcinogens. Their movement, transformation, and subsurface remediation is therefore of interest (Löffler et al., 2000). Among the chlorinated solvents, tetrachloroethene (PCE), trichloroethene (TCE), carbon tetrachloride (CT), and trichlormethane (CF) are common subsurface contaminants (ATSDA 2005), therefore, in-situ treatment technologies that simultaneously detoxifies them is highly desirable. CT is of interest since a broad range of transformation products can be formed under anaerobic conditions by biotic and abiotic mechanisms (Vogel et al., 1987; Kriegman-King et al., 1992; Hashsham et al., 1995). Many groundwater sites are contaminated with mixtures of CAHs, including PCE and CT that were both used in dry cleaning (Bagley et al., 2000). These mixtures are problematic for subsurface bioremediation, since they may directly inhibit the other dehalogenation processes or required fermentation processes that supply hydrogen $\left(\mathrm{H}_{2}\right)$ required as an electron donor for the organohalogen-respiring bacteria (OHRB) Dehalococcoides mccartyi (Löffle and Edwards 2006). CT and especially CF have been observed to inhibit and potentially exert toxicity on reductive dehalogenation of PCE and TCE (Bagley et al., 2000; Maymó-Gatell et al., 2001; He et al., 2005; Weathers et al., 2000; Duhamel et al., 2002) including Desulfitobacterium strains (Futagami et al., 2006 and Futagami et al., 2013). CF has also been shown to be a strong inhibitor of anaerobic fermentation processes (Parkin and Owen 1986).

Abiotic transformation of CT has also been observed (Kriegman-King et al., 1992; Criddle and McCarty 1991; Ammonette et al., 2000; Butler and Hayes 2000). CT either directly hydrolizes to $\mathrm{CO}_{2}$ or under reducing conditions with electron donors such as sulfide ferrous iron or iron sulfide $\mathrm{CT}$ is transformed to $\mathrm{CS}_{2}$ and $\mathrm{CF}$. 
Biotransformation of CT and CF by mixed and pure cultures under methanogenic conditions resulted in the formation of dichloromethane (DCM) and $\mathrm{CO}_{2}$ (Bagely and Gossett 1995; Gupta et al., 1996a) while under sulfate $\left(\mathrm{SO}_{4}{ }^{2}\right)$ reducing and acetogenic conditions higher rates of CT and CF were transformed to DCM and $\mathrm{CO}_{2}$ (Egli et al., 1988; Egli et al., 1990; Freedman et al., 1995; Gupta et al., 1996b). The anaerobic biotransformation of high concentrations of CT ( 0.5 $\mathrm{mM}$ ) with hydroxocobalamin to end products of $\mathrm{CO}, \mathrm{CO}_{2}$ and organic acids has also been reported (Hashsham and Freedman 1999). In the presence of vitamin $B_{12}$ high concentrations of $\mathrm{CF}(4.0 \mathrm{mM})$ were transformed under anaerobic conditions to $\mathrm{CO}, \mathrm{CO}_{2}$ and organic acids (Shan et al., 2010a; Shan et al., 2010b).

Chung and Rittman (2007) and Chung and Rittman (2008) showed the simultaneous biotransformation of a low level mixture of TCE (7-18 $\mu \mathrm{M}) \mathrm{CF}(8-20 \mu \mathrm{M})$ and TCA $(7.5 \mu \mathrm{M})$ using a hydrogen-base membrane biofilm reactor under $\mathrm{SO}_{4}{ }^{2-}$ and nitrate reducing conditions. DCM and $\mathrm{CM}$ were the final $\mathrm{CF}$ transformation products with a possibility of the $\mathrm{CM}$ hydrolyzing to methanol. In batch experiments with a culture of Desulfovibrio vulgaris the sequential removal of PCE $(14 \mu \mathrm{M})$ and $\mathrm{CT}(10 \mu \mathrm{M})$ showed $\mathrm{CS}_{2}$ was the major CT transformation possibly due to sulfide production (Koenig and Lee 2012). Previous column studies of PCE and CT transformation indicated the simultaneous transformation could be achieved, however inhibition of PCE transformation to ethene and propionate fermentation occurred (Bagley et al., 2000; Kaseros et al., 2000).

The goal of this study was to achieve the simultaneous anaerobic transformation of PCE and CT and to study the effects of different electron donors lactate or formate on the transformations. The study was conducted in a continuous flow column packed with quartz Ottawa sand. The column was bioaugmented with Evanite culture (EV) that contains strains of 
Dehalococcoides mccartyi (Dhc) (Behrens et al., 2008; Marshall et al., 2013) that is capable of transforming PCE to ethene (ETH) (Yu et al., 2005). The reductive dehalogenase $(r d h)$ genes in the Evenite culture were identified as being closely related to the population of Dhc previously found under chemostat growth conditions (Marshall et al., 2013; Mayer-Blackwell et al., 2014), where Dhc, Geobacter, and Desulfitobacterium strains were also present. Dhc require for grow on reduced organic compounds as carbon source (e.g. acetate or lactate) (He et al., 2003; Müller et al., 2004). The $16 S$ rRNA gene abundance for Dehalococcoides and Geobacter compared with gene counts of hypothesized vinyl-chloride (VC) respiring strains $(v c r A)$ and putative vinylchloride reductase ( $b v c A)$ were similar (Mayer-Blackwell et. al., 2014). $v c r A$ and $b v c A$ strains are known to reduce 1,2-dichloroethene (DCE) and VC to ETH (Müller et al., 2004; KrajmalnikBrown et al., 2004). The culture was not previously acclimated to CT transformation. The concentration effect of $\mathrm{H}_{2}$ on PCE dehalogenation was also investigated as well as $\mathrm{SO}_{4}{ }^{2-}$ as a competitive electron acceptor. The studies were conducted as a series of long-term transient tests that permitted pseudo-steady-state conditions to be achieved and electron balances of the donor and acceptor processes. The transient production of intermediate products from CT transformation was also monitored. Studies of PCE transformation and $\mathrm{SO}_{4}{ }^{2-}$ reduction performed after the CT transformation tests evaluated whether the lactate fermentation or the production of $\mathrm{H}_{2}$ through formate addition was negatively impacted.

2. Materials and methods

\subsection{Chemicals}

Analytical grade CAHs and ETH for the column influent feed or for analytical standards were used: (PCE, 99.9\%; CF, 99.5\%; and c-DCE, 97\%; Acros Organics) (VC, 99.5\%; CT, 99.9\%; 
CM, 99.5\%; and ETH 99.5\% Aldrich Chemical) (formate, 99.0\%; lactate, 60\%; syrup, J.T. Baker) and ( $\mathrm{H}_{2}, 99.999 \%$; Airgas Inc.).

\subsection{Column Construction and Operation}

The studies were conducted in a fabricated stainless steel column (standard molybdenum-bearing grade $316,30 \mathrm{~cm} \mathrm{~L} \mathrm{x} 7.5 \mathrm{~cm}$ ID) packed with quartz Ottawa sand (20/30 mesh; Langston Company Inc). Prior to column packing the Ottawa sand was autoclaved. The column was packed wet as described by Azizian et al., (2008) resulting in a porosity of 0.36 and a pore volume of $476 \mathrm{~mL}$. PEEK tubing (1/8” OD) (Upchurch Scientific) with a low $\mathrm{O}_{2}$ permeability was used for the pumping of the influent reservoirs and sampling valves and fittings that were connected to the column (Azizian et al., 2008).

The column was amended with synthetic groundwater containing a biocarbonate buffer (3.5 mM) supplemented with 1/10 dilution of anaerobic growth media described by Yu et al. (2005) to which was added PCE $(0.1 \mathrm{mM})$ lactate $(0.67-1.1 \mathrm{mM})$ or formate $(1.5-2.1 \mathrm{mM})$

and $\mathrm{SO}_{4}{ }^{2-}(0-0.2 \mathrm{mM})$ (Table 1$)$. The influent feed (100 ml/day) was added to the column using a syringe pump (M361, Thermo Scientific Orion) via a $100 \mathrm{ml}$ gas tight syringe. This flow rate resulted in a fluid hydraulic residence time in the column of 4.8 days.

\subsection{Bioaugmentation Culture}

The column was bioaugmented with the EV mixed dehalogenating culture that contained at least two strains of Dehalococcoides mccartyi (Marshall et al., 2013). Molecular characterization of the EV culture in a previous column study where the EV was bioagumented showed $73 \%$ of bacteria in the EV culture were strains of Dhc (Azizian et al., 2008). In that study after 170 days of column operation all four RDase genes ( $p c e A$, tceA, $b v c A$, and $v c r A$ ) were found (Behrens et al., 2008). Prior to bioagumentation the EV culture grown in sequential batch mode and fed PCE 
and butanol as a fermenting substrate with no exposure to CT. Bioaugmentation was accomplished by adding $50-\mathrm{ml}$ of liquid culture $(75 \mathrm{mg} / \mathrm{L}$ on a protein basis) to the column influent as a slug input.

\subsection{Analytical Methods}

Aqueous samples of the column's influent and effluent were analysed for the CAHs, ETH, $\mathrm{CS}_{2}, \mathrm{CO}, \mathrm{H}_{2}$, and $\mathrm{CH}_{4}$ using a headspace method as described by Azizian et al., 2008. The chlorinated ethenes and ETH were quantified with a HP-6890 gas chromatograph equipped with a flame ionization detector (FID). CT, CF, and DCM were quantified with a HP-6890 GC equipped with an electron capture detector (ECD) while CM was quantified with a HP-5890 GC equipped with an electrolyte conductivity detector (ELCD). The detection limits for PCE, TCE c-DCE, and ETH were 50, 8, 10, and $5 \mathrm{nM}$ respectively. The detection limits for CT, CF, and DCM were approximately 1080 and $100 \mathrm{nM}$ respectively and $5 \mathrm{nM} \mathrm{CM}$.

$\mathrm{H}_{2}$ concentrations in the column effluent were analyzed using a reduction gas detector (RGD) (Trace Analytical, ta3000R) (Azizian et al., 2010) with an aqueous concentration detection limit of $0.05 \mathrm{nM}$. CO was determined by HP-5890 GC with a thermal conductivity detector with packed column (Supelco 15' x 1/8" SS support 60/80 Carboxen 1000) with helium $\left(20 \mathrm{ml} / \mathrm{min}\right.$ ) as the carrier gas with a detection limit of $20 \mathrm{nM} . \mathrm{CH}_{4}$ and $\mathrm{CS}_{2}$ were measured by GC with FID and ECD detectors respectively. The detection limit for $\mathrm{CH}_{4}$ was $60 \mathrm{nM}$ and for $\mathrm{CS}_{2} 20 \mathrm{nM}$.

Formate lactate propionate and acetate concentrations were determined using high performance liquid chromatography (HPLC) on a Dionex DX500 HPLC (Azizian et al., 2008). Liquid samples $(0.25 \mathrm{~mL})$ of the column influent and effluent were centrifuged ( 2 min at 14,000 RPM) and diluted (1/10) with ultrapure water prior to analysis. Sulfate concentrations were 
determined using a Dionex DX-500 ion chromatograph equipped with an electrical conductivity detector and a Dionex AS14 column (Azizian et al., 2008). Total biomass in the column effluent was determined by filtering $100 \mathrm{~mL}$ of solution through $0.2 \mathrm{uM}$ Millipore filter drying the filter for $1 \mathrm{~h}$ at $105^{\circ} \mathrm{C}$ and weighing.

\subsection{Stages of the Column Study}

The column study was conducted over a period of 1950 days in ten Stages based influent solution chemical composition (Table 1). Each Stage was conducted for an extended time period so that pseudo-steady-state conditions were achieved with respect to effluent concentrations of CAHs ethene organic acids and $\mathrm{H}_{2}$. PCE reductive dehalogenation in the absence of $\mathrm{CT}$ was conducted in Stages I to VI over 1640 days. Dehalogenation performance was evaluated using different influent concentrations of lactate or formate as electron donors and in the presence and absence of $\mathrm{SO}_{4}{ }^{2-}$ as a competing electron acceptor. The simultaneous transformation of PCE $(0.1$ $\mathrm{mM})$ and CT (0.015 mM) was studied in Stage VII. A stop-flow experiment was performed in Stage VIII to determine if CF was completely transformed with a longer reaction time. Stages IX and X studied the effect that CT and CF exposure had on lactate fermentation homoacetogenesis and PCE transformation. Electron donor and accept balances were performed when pseudo-steady-state was obtained at the end of each Stage using methods described by (Azizian et al., 2010).

\section{Results}

3.1. Stages I to III - Bioaugmentation and PCE transformation with lactate addition Stage I prior to lactate addition and bioaugmention shows the rapid PCE breakthrough towards the injected concentrations $(0.1 \mathrm{mM})$ with no transformation occurring and little 
retardation due to sorption (Fig. 1a). In Stage II lactate addition was initiated on day 13 and bioaugmentation with the EV culture on day15. A transient build-up TCE concentration occurred and after 50 days PCE is mainly transformed to c-DCE (Fig. 1a). In previous column studies with Hanford aquifer material the transient c-DCE concentrations increased above the injection concentration of PCE which indicated transformation of sorbed PCE (Azizian et al., 2008; Azizian et al., 2010). This did not occur in Stage II which is consistent with minimal retardation of PCE observed in Stage 1. The minimal sorption of PCE is consistent with the very low carbon content of Ottawa sand (Zhuang et al., 2003).

Lactate was fermented to acetate and propionate however $\mathrm{SO}_{4}{ }^{2-}$ reduction was initially not observed (Fig. 1b). Electron donor and acceptor balances at the end of Stage II (Table 2) show 7.3\% was associated with CAHs transformation $30.8 \%$ with acetate and propionate production while a large fraction (55\%) was missing. Some of the missing balance was likely associated with biomass growth in the column and iron reduction in this early stage.

In Stage III the lactate influent concentration was increased to $1.1 \mathrm{mM}$ to promote more effective dehalogenation and potentially $\mathrm{SO}_{4}{ }^{2-}$ reduction. Acetate and propionate concentrations increased to maximum concentrations of approximately $0.3 \mathrm{mM}$ and $\mathrm{SO}_{4}{ }^{2-}$ was rapidly reduced (Fig. 1b). The accumulated c-DCE was transformed to ethene and VC, with a transient increase in VC concentration observed. Pseudo-steady-state effluent concentrations were achieved showing PCE was transformed to ethene $(88.3 \%)$ and VC (11.2\%) (Table 1). Electron balances (Table 2) show about $7.1 \%$ of electron donor equivalents were associated with CAHs transformation while $24.9 \%$ were associated with $\mathrm{SO}_{4}{ }^{2-}$ reduction. The increase addition of lactate and the observed increase in propionate concentration likely resulted in propionate fermentation and likely an increase in the $\mathrm{H}_{2}$ concentration. The measurement of aqueous $\mathrm{H}_{2}$ 
concentrations commenced at the end of Stage III (Figure 2b), where approximately $20 \mathrm{nM} \mathrm{H}_{2}$ was observed. This $\mathrm{H}_{2}$ level is consistent with past column studies were propionate fermentation resulted in effective transformation of TCE to ethene (Azizian et al. 2010).

3.2. Stages IV-VI - Evaluation of formate addition as an electron donor

In Stage IV lactate was replaced by formate as an alternative electron donor. The formate influent concentration of $2.1 \mathrm{mM}$ represented $64 \%$ of electron donor potential as $1.1 \mathrm{mM}$ lactate. In response the effluent ethene concentration decreased slightly and $\mathrm{VC}$ concentration increased (Table 1) while complete reduction of $\mathrm{SO}_{4}{ }^{2-}$ was maintained (Fig. 2). Since lactate was not being fermented the propionate concentration decreased while acetate concentrations remained fairly constant likely due to homoacetogenesis. The measurement of $\mathrm{H}_{2}$ concentrations commenced at the end of Stage III. Formate addition maintained fairly high effluent $\mathrm{H}_{2}$ concentration of $19 \mathrm{nM}$ (Fig. 2b). The percentage of electron equivalents utilized for chloroethene (CE) dechlorination increased with formate addition compared to lactate (Table 2) which is consistent with past column studies (Azizian et al., 2010). Acetate production represented about $34 \%$ of the electron equivalents which is also consistent with previous column results (Azizian et al. 2010).

The formate influent concentration was lowered to $1.5 \mathrm{mM}$ in Stage $\mathrm{V}$ in order to study the dependence of PCE transformation and $\mathrm{SO}_{4}{ }^{2-}$ reduction on formate concentration. An immediate decrease in ethene concentration and increase c-DCE and VC concentrations occurred that was associated with $\mathrm{H}_{2}$ concentrations decreasing from 20 to $5 \mathrm{nM}$. (Fig. 2). The acetate concentration decreased while $\mathrm{SO}_{4}{ }^{2-}$ reduction below the detection limit of $0.01 \mathrm{mM}$ continued. The results are consistent with past columns studies were $\mathrm{SO}_{4}{ }^{2-}$ reduction effectively competed with c-DCE and VC dehalogenation under electron donor limited conditions (Azizian et al., 2010). 
A gradual improvement in dehalogenation performance occurred over the period of 640 to 1400 days. By the end of Stage V PCE was transformed to ETH (55\%) VC (33\%) and c-DCE (11\%) (Table1). $\mathrm{H}_{2}$ and acetate concentrations remained relatively constant during this period. An interesting observation is that formate increased in the column. One possible explanation for the improvement in dehalogenation performance with time is a population shift over time to strains of Dehalococcoides mccartyi that more effectively competed for the lower $\mathrm{H}_{2}$ concentrations. At the end of Stage $\mathrm{V}$ the percentage of electron donor associated with dehalogenation reactions increased to $26 \%$ while $\mathrm{SO}_{4}{ }^{2-}$ reduction represented $55 \%$ and acetate 7\%. Thus under electron donor limited conditions effective electron transfer to dehalogenation reactions was achieved using formate.

In order to further evaluate $\mathrm{SO}_{4}{ }^{2-}$ competition as a competing electron acceptor $\mathrm{SO}_{4}{ }^{2-}$ addition was stopped after 1400 days (Stage VI) while maintaining the influent formate (1.5 $\mathrm{mM}$ ). In response ethene concentrations increased and c-DCE and VC decreased (Fig. 2a). The termination of $\mathrm{SO}_{4}{ }^{2-}$ addition resulted in an increase in formate effluent to $0.40 \mathrm{mM}$ and increase in $\mathrm{H}_{2}$ concentrations from $5 \mathrm{nM}$ to $19 \mathrm{nM}$. Very effective electron donor efficiency was achieved during Stage VI with $48 \%$ associated with dehalogenation reactions and $12 \%$ to acetate formation.

\subsection{Stages VII - Simultaneous PCE and CT Transformation}

CT (0.015 mM) was continuously added in Stage VII while maintaining PCE (0.1 mM) and formate $(1.5 \mathrm{mM})$ addition, however $\mathrm{SO}_{4}{ }^{2-}$ was not added (Table 1). After 25 days of CT addition CT reached a maximum concentration of $0.009 \mathrm{mM}$ and then concentrations decreased to below detection (10 nM) (Fig. 3b). CF was produced as an intermediate product and reached 
a maximum concentration of $0.006 \mathrm{mM}$ followed by a decrease to a pseudo-steady-state effluent concentration of $0.003 \mathrm{mM}$ (Fig. 2b), which represented $20 \%$ of the CT transformed. A trace amount of CM ( 10 nM) and DM (data not shown) were detected (Fig. 2b), however $\mathrm{CH}_{4}, \mathrm{CO}$, or $\mathrm{CS}_{2}$ were not detected.

In response to $\mathrm{CT}$ addition and $\mathrm{CF}$ production acetate concentrations decreased to below the detection limit (0.01 mM) (Fig. 2c) and the formate effluent concentration increased to about $1.0 \mathrm{mM}$ which is approximately $66 \%$ of the influent formate. The increase in formate corresponded to dramatic increase in $\mathrm{H}_{2}$ concentrations to $160 \mathrm{nM}$. The increase in formate and $\mathrm{H}_{2}$ and decrease in acetate supports the inhibition of homoacetogenesis that coincided with CT addition and $\mathrm{CF}$ production. The high $\mathrm{H}_{2}$ concentrations $(160 \mathrm{nM})$ did not result in complete transformation of VC to ethene. The presence of CF may inhibit the rate of VC transformation to ethene. Acetate production was also inhibited, and past studies have shown that acetate is needed as a carbon source by Dehalococcoides mccartyi (He et al., 2003). Thus inhibited acetate production may also have been a limiting factor.

A slight increase in ethene concentration and decrease in c-DCE and VC occurred (Fig. 2a) in response to the CT addition. This enhanced dehalogenation performance was likely associated with the increase in $\mathrm{H}_{2}$ concentrations. At pseudo-steady state electron balances showed that about $71 \%$ of the electron equivalents were directed towards chlorinated ethene reduction and $1.0 \%$ with $\mathrm{CF}$ formation (Table 2). The inhibition of acetogenesis and incomplete formate utilization resulted in a very high percentage of the electron donor being associated with dehalogenation reactions.

\subsection{Stage VIII - Stop Flow Test}


Flow to the column was stopped after 140 days of CT addition (Stage VIII) while the CAHs, CT, CF, $\mathrm{H}_{2}$ and formate concentrations of samples from the effluent port were periodically measured. The influent solution was added only to displace the fluid sampled as described by Niemit and Semprini (2005). During the stop-flow Stage CF, CM, and VC concentrations gradually decreased while ETH increased (Fig. 3a and 3b) and no additional transformation products were detected. The formate concentration also decreased along with the $\mathrm{H}_{2}$ concentration. The stop-flow test showed with longer reaction time $\mathrm{CF}$ and VC continued to be transformed with only ETH from PCE transformation observed. CT was completely transformed to unknown product(s). It is possible that the Ehc population had not completely developed during the early stage of the column study and incomplete transformation to ethene was limited by the residence time in the column.

\subsection{Stage IX - Evaluation of the inhibition of lactate fermentation}

Stage IX evaluated whether lactate fermentation was inhibited in response to the prior addition of CT and CF production. Lactate $(1.1 \mathrm{mM})$ and PCE $(0.1 \mathrm{mM})$ were continuously added in the absence of both $\mathrm{SO}_{4}{ }^{2-}$ and $\mathrm{CT}$ addition. Lactate was completely transformed however it fermentation was incomplete as indicated by the build-up of acetate $(0.36 \mathrm{mM})$ and propionate $(0.48 \mathrm{mM})$ (Fig. $3 \mathrm{c})$ and decrease in $\mathrm{H}_{2}$ concentration below detection. While PCE continued to be completely transformed ETH concentrations decreased and VC and c-DCE were the major transformation products. In order to determine if $\mathrm{SO}_{4}{ }^{2-}$ reduction was also inhibited $\mathrm{SO}_{4}{ }^{2-}$ addition $(0.2 \mathrm{mM})$ was initiated after 1850 days. No detectable $\mathrm{SO}_{4}{ }^{2-}$ reduction was observed (Fig. 3c) as sulfate increased to the injected concentration. 
The influent chemical composition at the end of Stage IX matched those of Stage III (Fig. 1). Transformation to VC and ethene was greatly reduced in Stage IX compared to that achieved in Stage III (Table 1). The amount of propionate and acetate produced was also much greater in Stage IX (Fig. 3c) compared to III (Fig. 1c). Electron balances for Stage IX showed that $19.4 \%$ and $44.4 \%$ of the electron equivalents were associated with acetate and propionate production respectively while CAHs consumed only $2 \%$ compared to $7 \%$ in Stage III (Table 2). The results illustrate that the addition of $\mathrm{CT}$ and the production of $\mathrm{CF}$ had a negative impact on propionate fermentation which negatively impacted dehalogenation and $\mathrm{SO}_{4}{ }^{2-}$ reduction by limiting $\mathrm{H}_{2}$ production. A shift in the microbial community likely occurred in response to $\mathrm{CF}$ exposure.

3.6. Stage $\mathrm{X}$ - Evaluation of the inhibition of homoacetogensis through formate addition In Stage X lactate $(1.1 \mathrm{mM})$ was replaced by formate $(1.5 \mathrm{mM})$ to determine whether acetate production was still inhibited and whether effective dehalogenation and $\mathrm{SO}_{4}{ }^{2-}$ reduction could be restored. Acetate concentrations decreased below detection indicating acetate production was still not occurring. The inhibition of acetate production resulted in high $\mathrm{H}_{2}$ concentrations (44 nM) and formate not being completely utilized (Fig. 3c). However very effective transformation of PCE to ethene (98\%) was achieved with only a minor amount of VC (1.0\%) observed in the column effluent (Fig. 3a).

The results of Stage $\mathrm{X}$ were conducted under the same influent conditions as Stage V (Fig. 2) which was prior to CT addition. In comparison dehalogenation was more effective in Stage $\mathrm{X}$ with $\mathrm{H}_{2}$ concentration of $44 \mathrm{nM}$ compared to 6 - $8 \mathrm{nM}$ in StageV when acetate was formed. Electron balances showed 33\% of electrons were utilized toward $\mathrm{CAH}$ reduction compared to $25 \%$ in Stage V. The inhibition of homoacetogensis that resulted from CT addition 
and likely CF exposure continued in Stage X 105 days after the CT addition was terminated and corresponded to an increased PCE dehalogenation to ETH.

\section{Discussion}

\subsection{Effective long-term transformation of PCE to ethene}

Transformation of PCE to ETH was achieved over 1930 days in a continuous flow column with a single bioaugmentation of the EV culture. The most effective conversion of PCE to ETH (98\%) occurred in the Stage X (1885-1950 days) with formate following the simultaneous transformation of PCE and CT and the production of CF (Stages VII and VIII). The EV culture containing strains of Dehalococcides mccartyi which was not pre acclimated to CT or $\mathrm{CF}$ was able to tolerate influent CT concentration of $0.015 \mathrm{mM}(2.3 \mathrm{mg} / \mathrm{L})$ and $\mathrm{CF}$ effluent concentration of 0.003 to $0.006 \mathrm{mM}(\mathrm{CF})(0.35$ to $0.72 \mathrm{mg} / \mathrm{L})$. Effective fermentation of propionate and the production of acetate as a result of homoacetogeneis however were negatively impacted by CT addition and CF production.

\subsection{Comparison with previous column and microcosm studies}

Consistent with our past column studies (Azizian, et al., 2010) both lactate and formate were both effective substrates to promote dehalogenation of PCE to ethene. A higher percentage of electron transfer to dehalogenation reactions was achieved using formate than lactate (Table 2) which is also consistent with the results of Azizian, et al., (2010). In both studies when lactate was fermented significant amounts of the electron donor potential were lost in the production of acetate. In both studies sulfate reduction successfully competed with the dehalogenation reaction for electron donor. The aquifer material used in the study of Azizian, et al., (2010) had much higher iron content than the material used in this study and a significant amount of the electron donor was used for iron reduction and sulfate reduction. Therefore the efficiency of the electron 
donor directed to dehalogenation in that study 7 to $16 \%$ was generally lower than achieved in the present study prior to the addition of CT 7 to $26 \%$ (stages II to V). The highest efficiency directed to dehalogenation of $71 \%$ was achieve during the CT transformation test (stage VII) when acetate production was inhibited and formate was not completely utilized.

Column and microcosm studies of Bagley et al. (2000) showed CF produced through CT transformation inhibited PCE dehalogenation. In their column studies PCE dehalogenation could not be stimulated in the presence of $0.043 \mathrm{mM} \mathrm{CT}$ while feeding ethanol as a fermenting substrate. CT was transformed producing $\mathrm{CF}(0.022 \mathrm{mM})$ and DM $(0.006 \mathrm{mM})$ and acetate and propionic acid (propionate) accumulated. Microcosm tests confirmed the results of the column studies and supported earlier observations of CF inhibition of propionate-consuming anaerobic systems (Rhee and Speece 1992). They argue that the inhibition of dehalogenation may have resulted from the inhibition of propionate fermentation to produce $\mathrm{H}_{2}$ which is supported by our observations in Stage IX.

In the column study of Kaseros et al., (2000) PCE transformation to VC and ETH could acclimate to $\mathrm{CT}$ exposure and $\mathrm{CF}$ production with $\mathrm{CT}$ concentrations increasing from 3.3 to 13 $\mathrm{uM}$ while feeding ethanol as an electron donor. Ethanol degradation was not inhibited at the inlet CT concentrations and CF concentration of $3.0 \mathrm{uM}$ which is in the same range as our study however the further fermentation of propionate and utilization of acetate was completely inhibited. They indicated that PCE transformation was not likely inhibited since ethanol (2.2 $\mathrm{mM})$ and the yeast extract $(100 \mathrm{mg} / \mathrm{L})$ were added to produce enough reducing equivalents to reduce PCE $(0.03 \mathrm{mM})$. These concentrations represented higher excess donor conditions compared to our tests. They indicated the inhibition propionate fermentation would likely negatively impact PCE dehalogenation if it was needed as donor. This condition was confirmed 
in Stage IX of our study where lactate was completely degraded but acetate and propionate accumulated and the $\mathrm{H}_{2}$ concentration was reduced below $1 \mathrm{nM}$ due to the inhibition of propionate fermentation. Under these conditions PCE was transformed mainly to c-DCE and VC. 4.3. Relationship of PCE dehalogenation to aqueous $\mathrm{H}_{2}$ concentrations

The ability to measure low $\mathrm{H}_{2}$ concentrations was a key aspect of our column study. Fig. 4 shows the relationship of the extent of transformation of PCE to ETH versus the observed effluent $\mathrm{H}_{2}$ concentrations for different Stages. When the $\mathrm{H}_{2}$ concentrations were maintained above $30 \mathrm{nM}$ greater than $95 \%$ conversion of PCE to ETH was achieved. When the $\mathrm{H}_{2}$ concentration decreased below $10 \mathrm{nM}$ the conversion to ETH was greatly reduced. The resulting empirical relationship is for the conditions of this study and depends on many factors including donor supply competing acceptor reactions $\left(\mathrm{SO}_{4}{ }^{2-}\right.$ reduction) and inhibition of the propionate fermentation process. The fit shown in Fig. 4 is a Monod type of plot however the rate that should appear on the y-axis was replaced by the percent conversion to ETH for illustrative purposes. The transformation rates of c-DCE to $\mathrm{VC}$ and $\mathrm{VC}$ to $\mathrm{ETH}$ are dependent on $\mathrm{H}_{2}$ concentration (Cupples et al., 2004). Cupples et al., 2004 report a half-substrate coefficient $\left(\mathrm{K}_{\mathrm{s}}\right)$ for $\mathrm{H}_{2}$ of around $7 \mathrm{nM}$ for c-DCE and VC for the VS dehalogenating culture that contains $D$. mccartyi. If the EV culture had a similar $\mathrm{K}_{\mathrm{s}}$ value as the VS culture then the c-DCE and VC dehalogenation rates would be near maximum rates with respect to $\mathrm{H}_{2}$ when $\mathrm{H}_{2}$ concentrations were above $30 \mathrm{nM}$ but would be very significantly reduced below the $\mathrm{K}_{\mathrm{s}}$ value consistent with the trends shown in Fig. 4. The fitted concentration in Fig. 4 when 50\% of the PCE was transformed to ETH was $3.5 \mathrm{nM} \mathrm{H}_{2}$ which is half of the reported $\mathrm{K}_{\mathrm{s}}$ value (Cupples et al., 2004). 4.4. Inhibition of fermentation processes after the transformation of $\mathrm{CF}$ to $\mathrm{CT}$ 
Homoacetogenesis was inhibited during CT addition and CF production (Stage VII) and continued after the addition of CT was discontinued (Stage X) as indicated by the lack of acetate production and increased formate and $\mathrm{H}_{2}$ concentrations. CF inhibited homoacetogens in studies with microbes associated with excised roots of rice (Conard and Klose 2000). Studies with pure cultures of methanogens homoacetogens and $\mathrm{SO}_{4}{ }^{2-}$ reducing bacteria by Scholten et al. (2000) found $\mathrm{CF}$ inhibition was associated with microorganisms that operate the acetyl-CoA cleavage pathway. They found $\mathrm{CF}$ inhibited acetate production from $\mathrm{H}_{2}$ of the homoacetogen Acetobacterium woodi which was shown by Egli et al. (1988) to transform $\mathrm{CT}$ with $\mathrm{CO}_{2}$ being a major transformation product.

Microcosm studies with the EV culture (Yu and Semprini 2009) and column studies (Azizian et al., 2008) found methane was not produced likely as a result of exposure high PCE concentrations during long term culture maintenance consistent with observations of Yang and McCarty (1998). Thus $\mathrm{H}_{2}$ consuming methanogens did not out compete homoacetogens for $\mathrm{H}_{2}$ in the present study. While feeding formate $\mathrm{SO}_{4}{ }^{2-}$ reducers and homoacetogens were the main competitors for $\mathrm{H}_{2}$ with the dehalogenating population. When the formate concentration was decreased in Stage $\mathrm{V}, \mathrm{H}_{2}$ concentrations decreased from $20 \mathrm{nM}$ to $8 \mathrm{nM}$ and dehalogenation efficiency decreased while complete $\mathrm{SO}_{4}{ }^{2-}$ reduction was maintained. Sulfate reducing bacteria effectively competed for $\mathrm{H}_{2}$ with c-DCE and VC dehalogenators. When propionate fermentation was inhibited in Stage IX $\mathrm{SO}_{4}{ }^{2-}$ reduction was also inhibited indicating $\mathrm{H}_{2}$ was the preferred donor and not acetate which was present.

$\mathrm{CF}$ has been applied in activated sludge to increase $\mathrm{H}_{2}$ production by inhibiting methane production and acetate formation via homoacetogensis (Xu and Chen 2010). We also found in Stage VII that $\mathrm{H}_{2}$ concentrations were greatly increased $(160 \mathrm{nM})$ in the presence of $\mathrm{CF}$ and 
more effective dehalogenation was achieved (Table 2). Thus an important choice for bioremediation when a mixture of PCE and CT or chloroform is present is the donor added. Our study indicates that formate would be a better choice than lactate to achieve effective treatment. CT essentially completely transformed with a residence time of 4.5 days with $20 \%$ observed as CF. It is not know the contribution of biotic and abiotic processes to CT transformation in the column. It is possible that biotic cometabolic processes contributed to the $\mathrm{CT}$ transformation. The results show $\mathrm{CT}$ addition and $\mathrm{CF}$ accumulation inhibited acetate formation by homoacetogenes. Homoacetogenes have been observed to transform CT to CF DCM and soluble non-chlorinated products (Egli et al., 1988; Egli et al., 1990; Syed and Freedman 1999; Stromeyer et al., 1992). Egli et al. (1988) found Aceobacterium woodi and Clostridium theroaceticum ability to transform CT was associated with microorganisms that contained the acetyl-coenzyme A pathway, with $\mathrm{CO}_{2}$ being a major product formed and minor amounts through a reductive pathway of CF and DM. Hashsham et al. (1999) found enhanced biotransformation of CT was achieved by supplemented Acetobacterium woodi with hydroxocobalamin that also resulted in a shift from a reductive pathway of CF and DM formation to a pathway of $\mathrm{CO}$ formation and $\mathrm{CO}_{2}$ production. In our study $\mathrm{CO}$ was not observed as an intermediated product. Other studies shown that Dehalocbacter that can gain energy from the respiration of CF to DM has been observed (Grostern et al., 2010) and the reduction of CF to DM and it subsequent fermentation of DM to acetate (Lee et al., 2012) indicates the potential for other biotic pathways.

CT can also be transformed by abiotic processes involving sulfide minerals biotite and vermiculite (Kriegman-King and Reinhard 1992) and pyrite (FeS) (Kriegman-King and Reinhard 1992; Devlin and Müller 1999) producing CF and $\mathrm{CS}_{2}$. In the column study and batch studies 
with sulfate reduction (Devlin and Müller 1999) observed a $\mathrm{CF} / \mathrm{CS}_{2}$ production ratio of around 2:1. We did not observe $\mathrm{CS}_{2}$ in our study. Active sulfide reduction was not occurring during the Stage VII of CT transformation test; however it is possible that FeS was present in the column due to the production of sulfide through $\mathrm{SO}_{4}{ }^{2-}$ reduction. The Ottawa sand used to pack the column has a low iron content of $28.7 \mathrm{mg} / \mathrm{kg}$ solids (Zhuang et al., 2003) thus there was limited potential FeS production which is consistent with our not detecting $\mathrm{CS}_{2}$. The abiotic transformation of CT by bioreduced ferric iron produced iron reducing bacteria has been observed to be a dominant mechanism (McCormick et al., 2002; Maithreepala and Doong 2009) and may have occurred even at the low iron contents of the solids used. A strain of Geobacter has recently been shown to represent a significant fraction of the microbial population in a chemostat inoculated with the EV culture that is dehalogenating TCE to ethene with formate being fed as an electron donor (Mayer-Blackwell et al., 2014). Thus Geobacter was likely present in the EV culture used to bioaugment the column. One strain of Geobacter has been shown to carry $r d h$ genes and the capacity for growth linked to PCE-reduction (Sung et al. 2006).

CT was completely transformed and $20 \%$ was observed as CF. The other $80 \%$ was converted to an unknown product likely $\mathrm{CO}_{2}$. In a follow-up study we confirmed that $\mathrm{CO}_{2}$ was the main product formed through the addition of ${ }^{13} \mathrm{C}$ labeled CT (Semprini and Azizian 2014).

\section{Conclusions}

The following conclusions can be drawn from this study:

- PCE was effectively dehalogenated to ethene over a period of 1930 days in a continuous flow column fed either lactate or formate with a single bioaugmentation of the EV culture. 
- When formate was fed as the electron donor PCE continued to be effectively dehalogenated to ethene upon the addition of CT with the production of $\mathrm{CF}$ and other products.

- CT transformation to CF inhibited homoacetogenesis and the production of acetate when formate was fed as a substrate resulting in incomplete formate utilization high aqueous $\mathrm{H}_{2}$ concentrations and vary efficient utilization of donor for CE dehalogenation.

- Fermentation processes especially propionate fermentation was greatly inhibited after the exposure to $\mathrm{CT}$ and $\mathrm{CF}$ which resulted in low aqueous $\mathrm{H}_{2}$ concentrations and dehalogenation of PCE mainly to c-DCE and VC with the lack of sulfate reduction.

- However the most effective dehalogenation of PCE to ethene was achieved after the exposure to $\mathrm{CT}$ and $\mathrm{CF}$ when formate was used as an electron donor, and CT was no longer being added that produced $\mathrm{CF}$.

The results of this research indicate the careful consideration should be made as to the substrate used to drive reductive dehalgenation when mixtures of PCE and CT are present. Formate appears to be a better substrate than lactate since fermentation processed and microorganisms required to produce $\mathrm{H}_{2}$ needed for dehalogenation are greatly inhibited when $\mathrm{CF}$ is formed.

\section{Acknowledgments}

This study was supported by the Department of Defense Strategic Environmental Research and Development Program (SERDP) through the grant ER 1588 and by a grant through the SEED Program of the Korean Ministry of the Environment. 


\section{References}

Ammonette, J.E., Workman, D.J., Kennedy, D.W., Fruchter, J.S.G.Y.A., 2000. Dechlorination of carbon tetrachloride by Fe(II) associated with goethite. Environ. Sci. Technol. 34(21) 4606-4613.

ATSDR (Agent for Toxic Substances and Disease Registry) 2005. CERCLA priority list of hazardous substances that will be the subject of toxicology profile. http://www.atsdr.cdc.gov/SPL/index.html

Azizian, M.F., Behrens, S., Sabalowsky, A., Dolan, M.E., Spormann A.M., Semprini L., 2008. Continuous-flow column study of reductive dehalogenation of PCE upon bioaugmentation with the Evanite enrichment culture. J. Contam. Hydrol. 100 (1-2) 11-21.

Azizian, M.F., Marshall, I.P.G., Behrens, S., Spormann, A.M., Semprini L., 2010. Comparison of lactate formate and propionate as hydrogen donors for the reductive dehalogenation of trichloroethene in a continuous-flow column. J. Contam. Hydrol. 113(1-4) 77-92.

Bagley, D.M., Lalonde, M., Kaseros, V., Stasiuk, K.E., Sleep, B.E., 2000. Acclimation of anaerobic systems to biodegrade tetrachloroethene in the presence of carbon tetrachloride and chloroform. Water Res. 34(1) 171178.

Bagley, D.M., Gossett, J.M., 1995. Chloroform degradation in methanogenic methanol enrichment cultures and by Methanosarcina barkeri 227. Appl. Environ. Microbiol. 61(9) 3195-3201.

Behrens, S., Azizian, M.F., McMurdie, P.J., Sabalowsky, A., Dolan, M.E., Semprini, L., Spormann, A.M., 2008. Monitoring abundance and expression of 'Dehalococcoides' species chloroethene-reductive dehalogenases in a tetrachloroethene-dechlorinating flow column. Appl. Envir. Microbiol. 74(18) 5695-5703.

Butler, E.C., Hayes, K.F., 2000. Kinetics of the transformation of halogenated aliphatic compounds by iron sulfide. Environ. Sci. Technol. 34(3) 422-429.

Chung, J. Rittman, B. E., 2008. Simultaneous bio-reduction of trichloroethene trichloroethane and chloroform using a hydrogen-base membrane biofilm reactor. Water Sci. \& Technol. 58(3) 495-501.

Chung, J. Rittmann, B.E., 2007. Bio-reductive dechlorination of 111-trichloroethane and chloroform using a hydrogen-based membrane biofilm reactor Biotechnol. Bioeng. 97(1) 52-60.

Conrad, R., Klose, M., 2000. Selective inhibition of reactions involved in methanogenesis and fatty acid production on rice roots. FEMS Microbiol Ecol. 34(1) 27-34.

Criddle, C.S. McCarty, P.L. 1991. Electrolytic model system for reductive dehalogenation in aqueous environments. Environ. Sci. Technol. 25(5) 973-978.

Cupples, A.M., Spormann, A.M., McCarty P.L., 2004. Vinyl chloride and cis-dichloroethene dechlorination kinetics and microorganism growth under substrate limiting conditions. Environ. Sci. Technol. 38 (4) $1102-1107$.

Devlin, J.F., Müller, D., 1999. Field and laboratory studies of carbon tetrachloride transformation in a sandy aquifer under sulfate reducing conditions. Environ. Sci. Technol. 33(7) 1021-1027.

Duhamel, M., Wehr, S.D., Yu L., Rizvi H., Seepersad D., Dworatzek S., Cox E.E., Edwards E.A., 2002. Comparison of anaerobic dechlorinating enrichment cultures maintained on tetrachloroethene trichloroethene cis-dichloroethene and vinyl chloride. Water Res. 36(17) 4193-4202.

Egli, C., Stromeyer, S., Cook, A.M. T., Leisinger, T., 1990. Transformation of tetra- and trichloromethane to $\mathrm{CO}_{2}$ by anaerobic bacteria is a nonenzymic process. FEMS Microbiol. Lett. 68(1-2) 207-212.

Egli, C., Tsuchan, T., Scholtz, R., Cook A.M., Leisinger, T., 1988. Transformation of terachloromethane to dichloromethane and carbon dioxide by Acetobacterium woodii. Appl. Environ. Microbiol. 54(11) 28192824.

Freedman, D. L., Lasecki, M., Hashsham, S., Scholze, R., 1995. Accelerated biotransformation of carbon tetrachloride and chloroform by sulfate-reducing enrichment cultures. p. 123-138. In R. E. Hinchee A. Leeson and L. Semprini (ed.) Bioremediation of chlorinated solvents vol. 4. Battelle Press Columbus OH.

Futagami, T., Fukaki, Y.H., Takegawa, K., Goto M., Furukawa K., 2013. Evaluation of the inhibitory effects of chloroform on ortho-chlorophenol- and chloroethene-dechlorinating Desulfitobacterium strains. AMB Express. 3:30. Published online 2013 May 27. doi: 10.1186/2191-0855-3-30.

Futagami, T., Yamaguchi, T., Nakayama, S., Goto M. Furukawa, K., 2006. Effects of chloromethanes on growth of and deletion of the pce genecluster in dehalorespiring Desulfitobacterium hafniense strain Y51. Appl. Environ. Microbiol. 72(9) 5998-6003.

Grostern, A., Duhamel, M., Dworatzek, S., Edwards, E.A., 2010. Chloroform respiration to dichloromethane by a Dehalobacter population. Environ. Microbiol. 12 (4) 1053-1060. 
Gupta, M., Gupta, A., Suidan, M.T., Sayles, G.D., 1996b. Biotransformation rates of chloroform under anaerobic conditions. II. Sulfate reduction. Water Res. 30(6) 1387-1394.

Gupta, M., Sharma, D., Suidan, M.T., Sayles, G.D., 1996a. Biotransformation rates of chloroform under anaerobic conditions. I. Methanogenesis. Water Res. 30(6) 1377-1385.

Hashsham, S.A., Freedman, D.L., 1999. Enhanced biotransformation of carbon tetrachloride by Acetobacterium woodii upon addition of hydroxocobalamin and fructose. Appl. Environ. Microbiol. 65(10) 4537-4542.

Hashsham, S.A., Scholze, R., Freedman, D.L., 1995. Cobalamin-enhanced anaerobic biotransformation of carbon tetrachloride. Environ. Sci. Technol. 29(11) 2856-2863.

He, J., Ritalahti, K.M.,Yang, K.L., Koenigsberg, S.S., Löffler, F.E.. 2003. Detoxification of vinyl chloride to ethene coupled to growth of an anaerobic bacterium. Nature 424(3):62-65.

He, J., Sung, Y., Krajmalnik-Brown, R., Ritalahti, K.M., Löffler, F.E., 2005. Isolation and characterization of Dehalococcoides sp. strain FL2 a trichloroethene (TCE)- and 12-dichloroethene-respiring anaerobe. Environ. Microbiol.7(9) 1442-1450.

Kaseros, V.B., Sleep, B.E., Bagley, D.M., 2000. Column studies of the biodegradation of mixtures of tetrachloroethene and carbon tetrachloride. Water. Res. 34 (17) 4161-4168.

Koenig, J.C., Lee, M. J., Manefield, M., 2012 Successful microcosm demonstration of a strategy for biodegradation of a mixture of carbon tetrachloride and perchloroethene harnessing sulfate reducing and dehalorespiring bacteria. J. of Hazardous Materials. 169-175.

Krajmalnik-Brown, R., Hölscher, T., Thomson, I.N., Saunders, F.M., Ritalahti, K.M., Löffler, F.E., 2004. Genetic identification of a putative vinyl chloride reductase in Dehalococcoides sp. strain BAV1. Appl. Environ. Microbiol. 70: 6347-6351.

Kriegman-King, M.R., Reinhard, M., 1992. Transformation of carbon tetrachloride in the presence of sulfide biotite and vermiculite. Environ. Sci. Technol. 26(11) 2198-2206.

Lee, M., Low, A., Zemb, O., Koenig, J., Michaelsen, A., Manefield, M., 2012. Complete chloroform dechlorination by organochlorine respiration and fermentation. Environ. Microbiol. 14(4) 883-894.

Löffler, F.E., Edwards, E.A., 2006. Harnessing microbial activities for environmental cleanup. Curr. Opin. Biotechnol. 17(3) 274-284.

Maithreepala, R.A., Doong, R., 2009. Transformation of carbon tetrachloride by biogenic iron species in the presence of and electron shuttles. J. of Hazardous Materials. 164 337-344.

Marshall, I.P.G., Azizian, M.F., Semprini, L., Spormann, A.M., 2013. Inferring community dynamics of organohalide-respiring bacteria in chemostats by covariance of rdhA gene abundance. FEMS Microbio. Ecol. $1-13$.

Mayer-Blackwell, K., Azizian, M.F., Machak, C., Vitale, E., Carpani, G., de Ferra, F., Semprini, L., Spormann, A.M., 2014. Nanoliter qPCR platform for highly parallel quantitative assessment of reductive dehalogenase genes and populations of dehalogenating microoganisms in complex environments. Environ. Sci. Techno. 48(16) 9659-9667.

Maymó-Gatell, X., Nijenhuis, I., Zinder, S.H., 2001. Reductive Dechlorination of cis-12-Dichloroethene and Vinyl Chloride by "Dehalococcoides ethenogenes." Environ. Sci. Technol. 35(3) 516-521.

McCormick, M.L., Bouwer, E.J., Adriaens, P., 2002. Carbon tetrachloride transformation in a model iron-reducing culture: Relative kinetics of biotic and abiotic reactions. Environ. Sci. Techno. 36(3) 403-410.

Müller, J.A., Rosner, B.M., Von Abendroth, G., Meshulam-Simon, G., McCarty, P.L., Spormann, A.M., 2004. Molecular identification of the catabolic vinyl chloride reductase from Dehalococcoides sp. strain VS and its environmental distribution. Appl. Environ. Microbiol. 70: 4880-4888.

Niemit, M.R., Semprini, L., 2005. Column studies of anaerobic carbon tetrachloride biotransformation with Hanford aquifer material. Ground Water Monitoring and Remediation 25(3) 82-92.

Parkin, G.F., Owen, W.F., 1986. Fundamentals of anaerobic digestion of wastewater sludges. J. of Environ. Engr. $112(5)$ 867-920.

Rhee, E., Speece, R.E., 1992. Maximal biodegradation rates of chloroform and trichloroethylene in anaerobic treatment. Water Sci. Technol. 25(3) 121-130.

Scholten, J.C.M., Conrad, R., Stams, A.J.M., 2000. Effect of 2-bromo-ethane sulfonate molybdate and chloroform on acetate consumption by methanogenic and sulfate-reducing populations in freshwater sediment. FEMS Microbiol Ecol. 32(1) 35-42.

Semprini, L., Azizian, M.F., 2014. ${ }^{13}$ C Labeled Carbon Tetrachloride to Demonstrate Its Transformation to Carbon Dioxide in a Continuous Flow Column. Ninth International Symposium on Subsurface Microbiology. October 5-10 Pacific Grove CA. 
Shan, H., Kurtz, H.D. Jr., Freedman, D.L., 2010b. Evaluation of strategies for anaerobic bioremediation of high concentrations of halomethanes. Water Res. 44(5) 1317-1328.

Shan, H., Kurtz, H.D., Mykytczuk, N., Trevors, J.T., Freedman, D.L., 2010a. Anaerobic Biotransformation of High Concentrations of Chloroform by an Enrichment Culture and Two Bacterial Isolates. Appl. Environ. Microbiol. 76 (19) 6463-6469.

Stromeyer, S.A., Stumpf, K., Cook, A.M., Leisinger, T., 1992. Anaerobic degradation of tetrachloromethane by Acetobacterium woodii: separation of dechlorinative activities in cell extracts and roles of vitamin B12 and other factors. Biodegradation (3) 113-123.

Sung, Y.; Fletcher, K. E.; Ritalahti, K. M.; Apkarian, R. P.; Ramos-Hernández, N.; Sanford, R. A.; Mesbah, N. M.; Löffler, F. E. Geobacter lovleyi sp. nov. strain SZ, a novel metal-reducing and tetrachloroethene-dechlorinating bacterium. Appl. Environ. Microbiol. 2006, 72, 2775-2782.Syed, A.H., Freedman, D. L., 1999. Enhanced biotransformation of carbon tetrachloride by acetobacterium woodii upon addition of hydroxocobalamin and fructose. Appl. Envir. Microbiol. 65 (10) 4537-4542.

Vogel, T.M., Criddle, C.S., McCarty, P.L., 1987. Transformation of halogenated aliphatic compounds. Environ. Sci. Technol. 21(8) 722-736.

Weathers, L.J., Parkin, G.F., 2000. Toxicity of chloroform biotransformation to methanogenic bacteria. Environ. Sci. Technol. 34 (13) 2764-2767.

Xu, K., Liu, H., Chen, J., 2010. Effect of classic methanogenic inhibitors on the quantity and diversityof archaeal community and the reductive homoacetogenic activity during the process of anaerobic sludge digestion. Bioresour. Technol. 10 2600-2607.

Yang, Y.R., McCarty, P.L., 1998. Competition for hydrogen within a chlorinated solvent dehalogenating anaerobic mixed culture. Environ. Sci. Technol. 32 (22) 3591-3597.

Yu, S., Dolan, M.E., Semprini, L., 2005. Kinetics and inhibition of reductive dechlorination of chlorinated ethenes by two different mixed cultures. Environ. Sci. Technol. 39(1) 195-205.

Yu, S., Semprini, L., 2009. Enhanced reductive dechlorination of PCE DNAPL with TBOS as a slow-release substrate. Journal of Hazardous Waste. 167(1-3) 97-104.

Zhuang, J., Usflury, M., Jin, Y., 2003. Colloid-facilitated Cs Transport through water-saturated Hanford sediment and Ottawa sand. Environ. Sci. Technol. 37(21) 4905-4911. 
Table 1: Summary of column operation conditions at different Stages electron donors $\mathrm{SO}_{4}{ }^{2-}$ and percentage of PCE transformed to the different products during pseudo-steady-state operation.

\begin{tabular}{|c|c|c|c|c|c|c|c|c|c|c|c|}
\hline \multirow[t]{3}{*}{ Stage } & \multirow{3}{*}{$\begin{array}{l}\text { Start } \\
\text { (day) }\end{array}$} & \multirow{3}{*}{$\begin{array}{c}\text { Steady- } \\
\text { state } \\
\text { (day) }\end{array}$} & \multirow{3}{*}{$\begin{array}{c}\text { Electron } \\
\text { donor }\end{array}$} & \multirow{2}{*}{\multicolumn{2}{|c|}{$\begin{array}{l}\text { Electron } \\
\text { donor conc. }\end{array}$}} & \multirow[t]{2}{*}{ Sulfate } & \multirow[t]{2}{*}{$\mathbf{H}_{2}$} & \multicolumn{4}{|c|}{ CAHs } \\
\hline & & & & & & & & ETH & $V C$ & $-D C E$ & $T C E$ \\
\hline & & & & $(\mathrm{mM})$ & (meq) & $(\mathrm{mM})$ & $(\mathrm{nM})$ & $\%$ & $\%$ & $\%$ & $\%$ \\
\hline$I$ & 0 & 12 & & \multicolumn{4}{|c|}{ Tracer Test } & & & & \\
\hline II & 12 & 50 & Lactate & 0.67 & 8.0 & 0.2 & $\mathrm{ND}^{\mathrm{a}}$ & 0.0 & 0.0 & 100 & 0.0 \\
\hline III & 50 & 200 & Lactate & 1.1 & 13.2 & 0.2 & ND & 88.3 & 11.2 & BDL & BDL \\
\hline IV & 250 & 500 & Formate & 2.1 & 4.2 & 0.2 & 18.7 & 81.3 & 17.1 & BDL & BDL \\
\hline $\boldsymbol{V}$ & 500 & 1400 & Formate & 1.5 & 3.0 & 0.2 & 6.8 & 54.7 & 32.6 & 10.5 & BDL \\
\hline$V I$ & 1400 & 1640 & Formate & 1.5 & 3.0 & 0.0 & 6.8 & 82.3 & 16.0 & 1.0 & BDL \\
\hline VII & 1640 & 1780 & Formate & 1.5 & 3.0 & 0.0 & 160 & 85.7 & 14.3 & BDL & BDL \\
\hline VIII & 1780 & 1850 & Stop Flow & & & & & & & & \\
\hline$I X$ & 1850 & 1885 & Lactate & 1.1 & 13.2 & 0.2 & 0.2 & 7.7 & 40.6 & 51.6 & BDL \\
\hline$X$ & 1885 & 1950 & Formate & 1.5 & 3.0 & 0.2 & 43.0 & 97.8 & 1.0 & BDL & BDL \\
\hline
\end{tabular}

$\mathrm{ND}^{\mathrm{a}}$ : not determined $\mathrm{BDL}^{\mathrm{a}}$ : below detection limit 
Table 2 Electron donor and electron acceptor balances with the percentage representing the donor associated with organic acid or biomass production or sulfate, chlorinated ethene (CE), and CT reduction.

\begin{tabular}{|c|c|c|c|c|c|c|c|c|}
\hline \multirow[t]{2}{*}{ Stage } & \multirow[t]{2}{*}{$\begin{array}{c}\text { Electron } \\
\text { donor }\end{array}$} & Acetate & Propionate & Sulfate & $\mathbf{C E}$ & $\mathbf{C F}$ & Biomass & $\begin{array}{c}\text { Electron donor } \\
\text { Accountable }\end{array}$ \\
\hline & & & \multicolumn{6}{|c|}{ Electrons (\%) } \\
\hline II & Lactate & 16.0 & 14.8 & 11.4 & 7.3 & NA & 5.6 & 55.1 \\
\hline III & Lactate & 22.8 & 21.8 & 24.9 & 7.1 & NA & 2.10 & 78.7 \\
\hline IV & Formate & 33.8 & 0.0 & 39.1 & 17.0 & NA & 1.64 & 91.5 \\
\hline $\boldsymbol{V}$ & Formate & 6.7 & 0.0 & 55.0 & 25.8 & NA & 1.77 & 89.3 \\
\hline$V I$ & Formate & 12.2 & 0.0 & 0.0 & 48.4 & NA & 3.0 & 63.6 \\
\hline VII & Formate & 0.0 & 0.0 & 0.0 & 71.3 & 1.0 & 9.8 & 82.1 \\
\hline VIII & Stop flow & & & & & & & \\
\hline$I X$ & Lactate & 19.4 & 44.4 & 8.3 & 2.2 & NA & 2.41 & 76.7 \\
\hline$X$ & Formate & 0.0 & 0.0 & 53.6 & 33.4 & NA & 7.87 & 94.9 \\
\hline
\end{tabular}

Dehalogenation/reduction reactions w/lactate as electron donor dehalogenation and fermentation products 1. $\mathrm{C}_{2} \mathrm{Cl}_{4}(\mathrm{PCE})+0.17 \mathrm{C}_{3} \mathrm{H}_{5} \mathrm{O}_{3}$ (Lactate) $+0.67 \mathrm{H}_{2} \mathrm{O}===\mathrm{C}_{2} \mathrm{HCl}_{3}(\mathrm{TCE})+\mathrm{HCl}+0.33 \mathrm{CO}_{2}+0.17 \mathrm{HCO}_{3}{ }^{-}$

2. $\mathrm{C}_{2} \mathrm{Cl}_{4}(\mathrm{PCE})+0.33 \mathrm{C}_{3} \mathrm{H}_{5} \mathrm{O}_{3}$ (Lactate) $+1.33 \mathrm{H}_{2} \mathrm{O}===>\mathrm{C}_{2} \mathrm{H}_{2} \mathrm{Cl}_{2}(\mathrm{c}-\mathrm{DCE})+2 \mathrm{HCl}+0.67 \mathrm{CO}_{2}+0.33 \mathrm{HCO}_{3}$

3. $\mathrm{C}_{2} \mathrm{Cl}_{4}(\mathrm{PCE})+0.51 \mathrm{C}_{3} \mathrm{H}_{5} \mathrm{O}_{3}$ (Lactate) $+2.01 \mathrm{H}_{2} \mathrm{O}===>\mathrm{C}_{2} \mathrm{H}_{3} \mathrm{Cl}(\mathrm{VC})+3 \mathrm{HCl}+1.00 \mathrm{CO}_{2}+0.51 \mathrm{HCO}_{3}^{-}$

4. $\mathrm{C}_{2} \mathrm{Cl}_{4}(\mathrm{PCE})+0.67 \mathrm{C}_{3} \mathrm{H}_{5} \mathrm{O}_{3}$ (Lactate) $+2.68 \mathrm{H}_{2} \mathrm{O}===>\mathrm{C}_{2} \mathrm{H}_{4}(\mathrm{ETH})+4 \mathrm{HCl}+1.33 \mathrm{CO}_{2}+0.67 \mathrm{HCO}_{3}{ }^{-}$

5. $\mathrm{C}_{3} \mathrm{H}_{5} \mathrm{O}_{3}^{-}$(Lactate) $+4.0 \mathrm{H}_{2} \mathrm{O}==>\mathrm{HCO}_{3}^{-}+2 \mathrm{CO}_{2}+6 \mathrm{H}_{2}$

6. $\mathrm{C}_{2} \mathrm{H}_{3} \mathrm{O}_{2}^{-}$(Acetate) $+3.0 \mathrm{H}_{2} \mathrm{O} \quad==>\mathrm{HCO}_{3}^{-}+\mathrm{CO}_{2}+4 \mathrm{H}_{2}$

7. $\mathrm{C}_{3} \mathrm{H}_{5} \mathrm{O}_{2}^{-}$(Propionate) $+6.0 \mathrm{H} 2 \mathrm{O}===>2 \mathrm{HCO}_{3}^{-}+\mathrm{CO}_{2}+7 \mathrm{H}_{2}+\mathrm{H}^{+}$

8. $\mathrm{C}_{3} \mathrm{H}_{5} \mathrm{O}_{3}{ }^{-}$(Lactate) $+1.5 \mathrm{SO}_{4}{ }^{2-}$ (Sulfate) $\quad==>1.5 \mathrm{~S}^{2-}+3 \mathrm{CO}_{2}+2.5 \mathrm{H}_{2} \mathrm{O}$

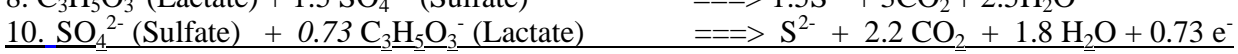

${ }^{a}$ Assumptions for computation of equivalents (mequiv/mmol): PCE 8 TCE 6 c-DCE 4 VC $2 \mathrm{H}_{2} 2$

formate 2 lactate 12 propionate 14 acetate 8 sulfate 8 . 
(b)

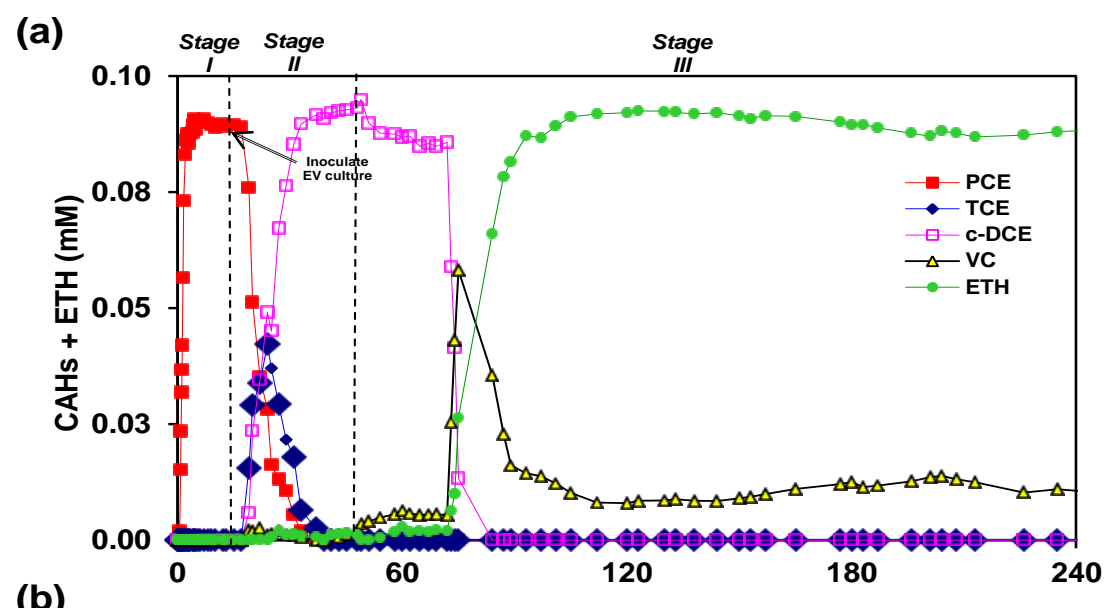

(b)

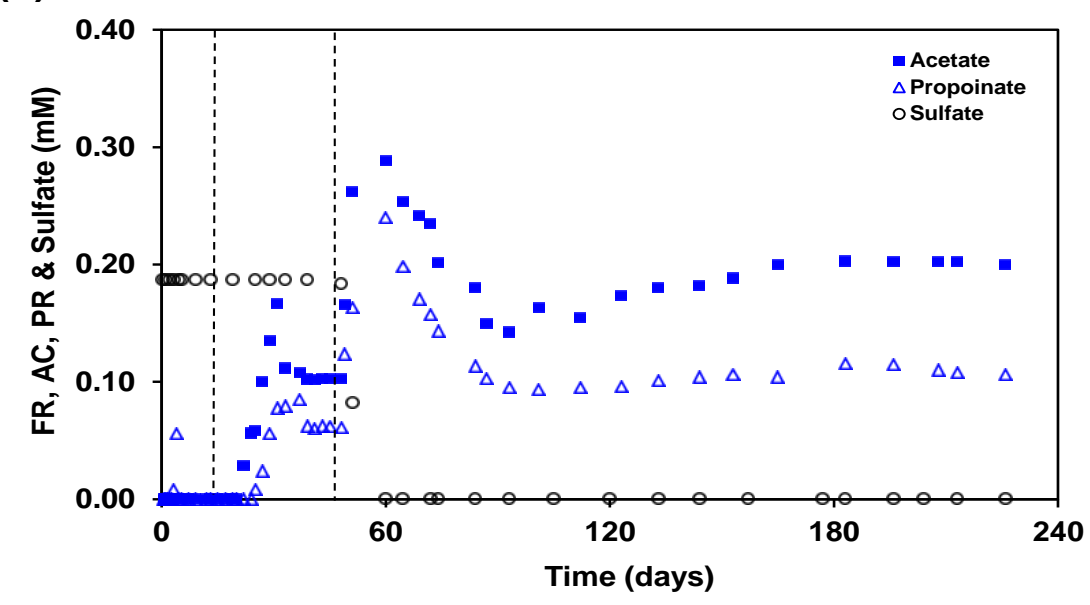

Fig. 1. Column effluent concentrations of (a) PCE, TCE, c-DCE, VC, and ETH and (b) organic acids and $\mathrm{SO}_{4}{ }^{2-}$ during Stages I to III. The dashed line denotes the start of the next Stage of the column study. 


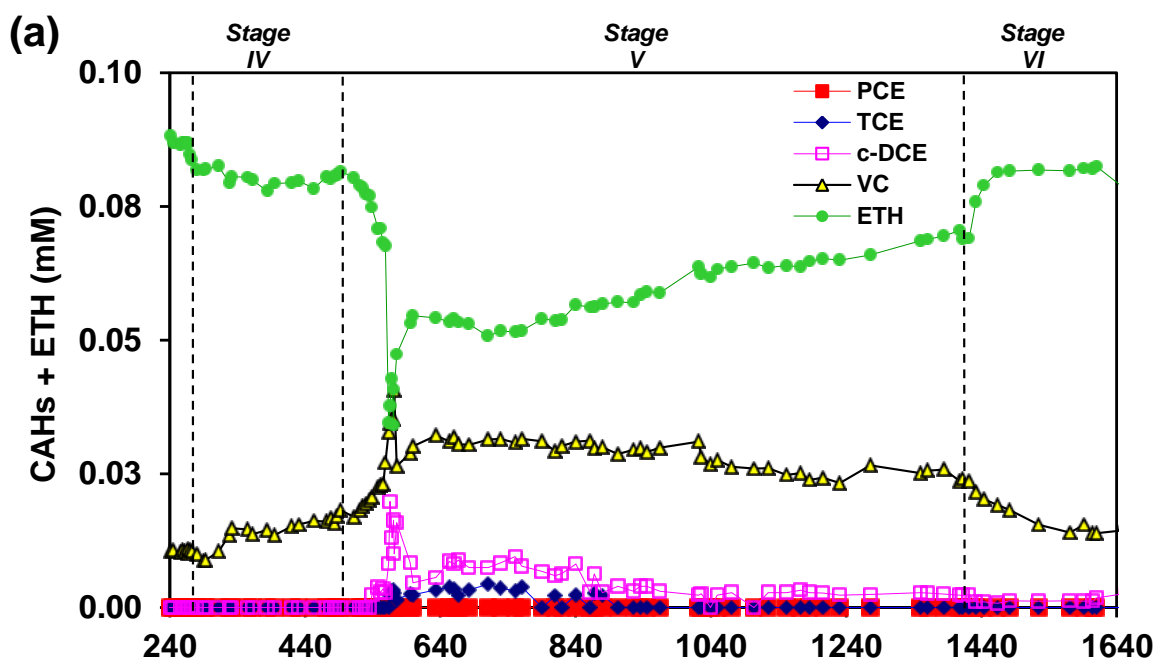

(b)

(b)

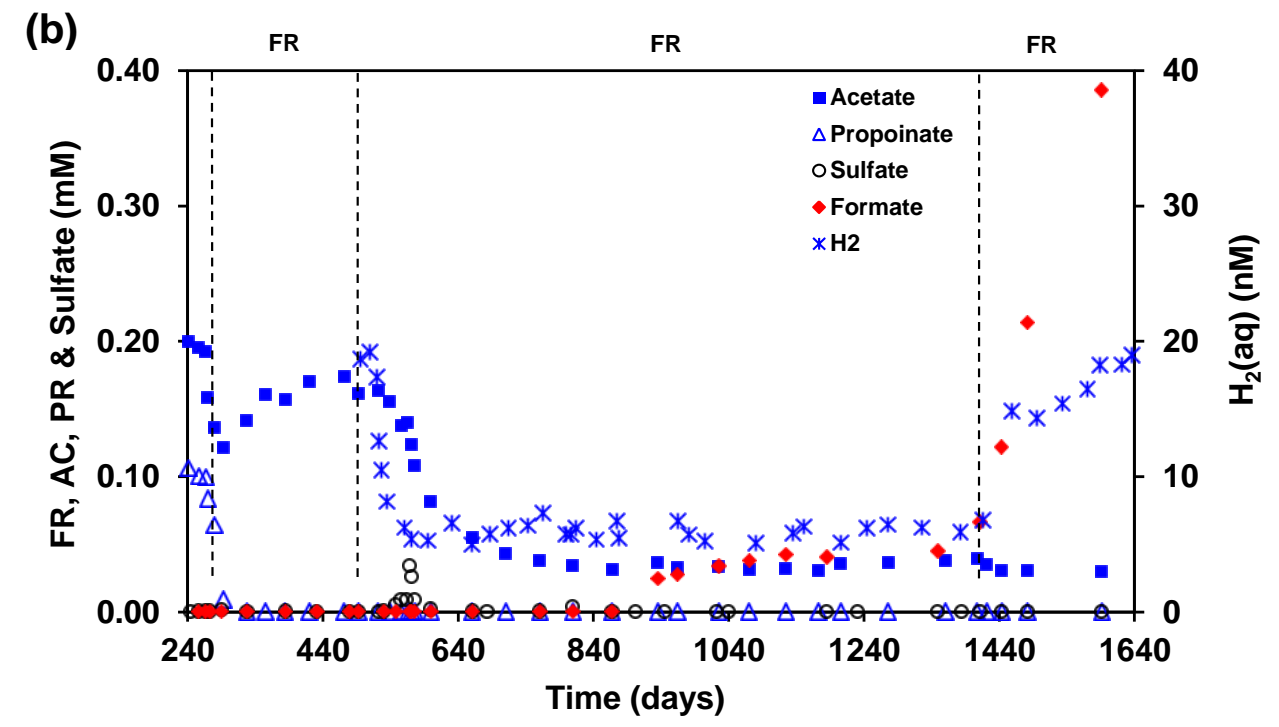

Fig. 2. Column effluent concentrations of (a) PCE, TCE, c-DCE, VC, and ETH and (b) organic acids $\mathrm{SO}_{4}{ }^{2-}$ and $\mathrm{H}_{2}$ during Stages IV to VI. The dashed line denotes the start of the next Stage of the column study. 

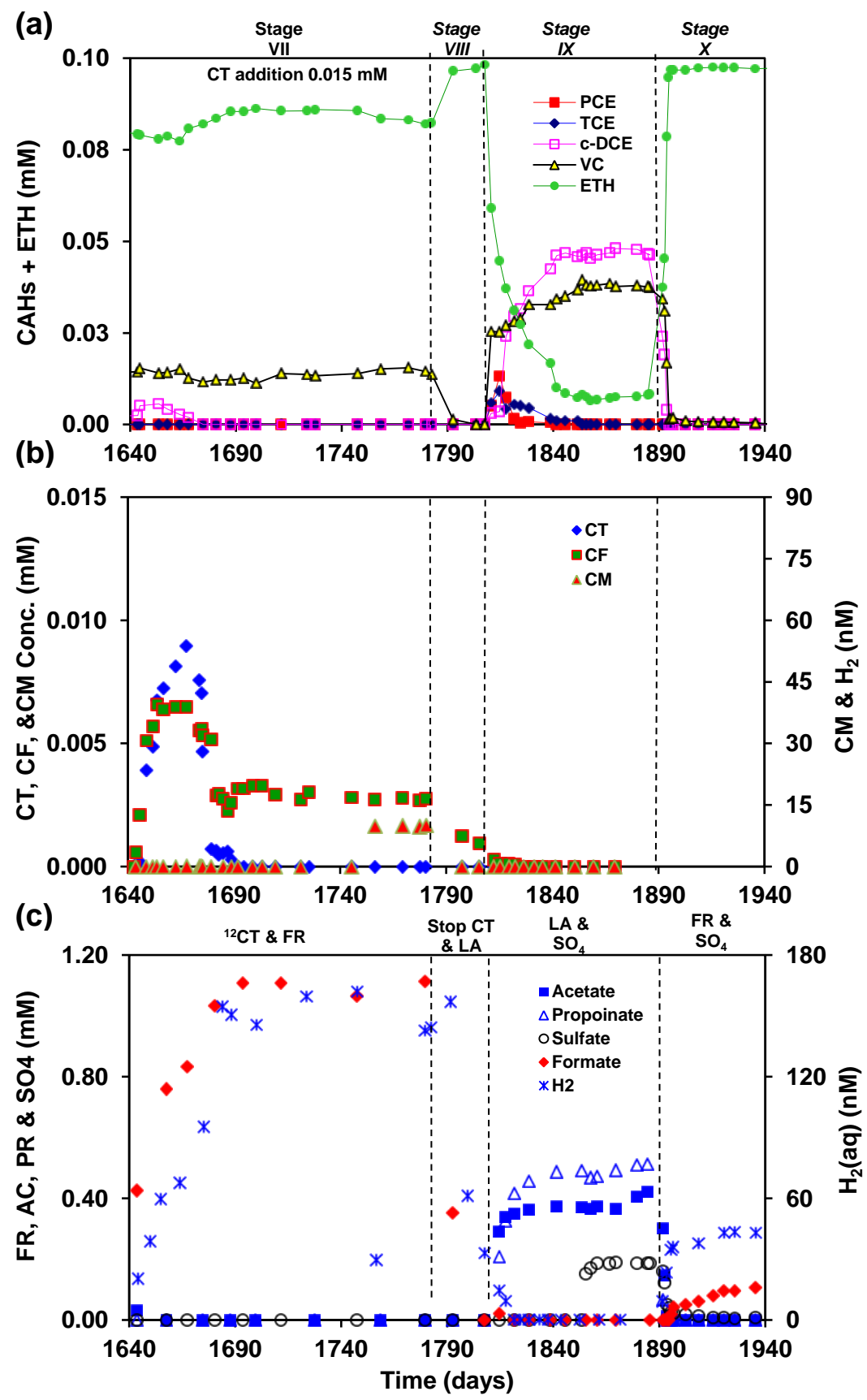

Fig. 3. Column effluent concentrations of (a) PCE, TCE, c-DCE, VC, and ETH (b) CT, CF, and $\mathrm{CM}$ and (c) organic acids $\mathrm{SO}_{4}{ }^{2-}$ and $\mathrm{H}_{2}$ during Stages VII to X. The dashed line denotes the start of the next Stage of the column study. 


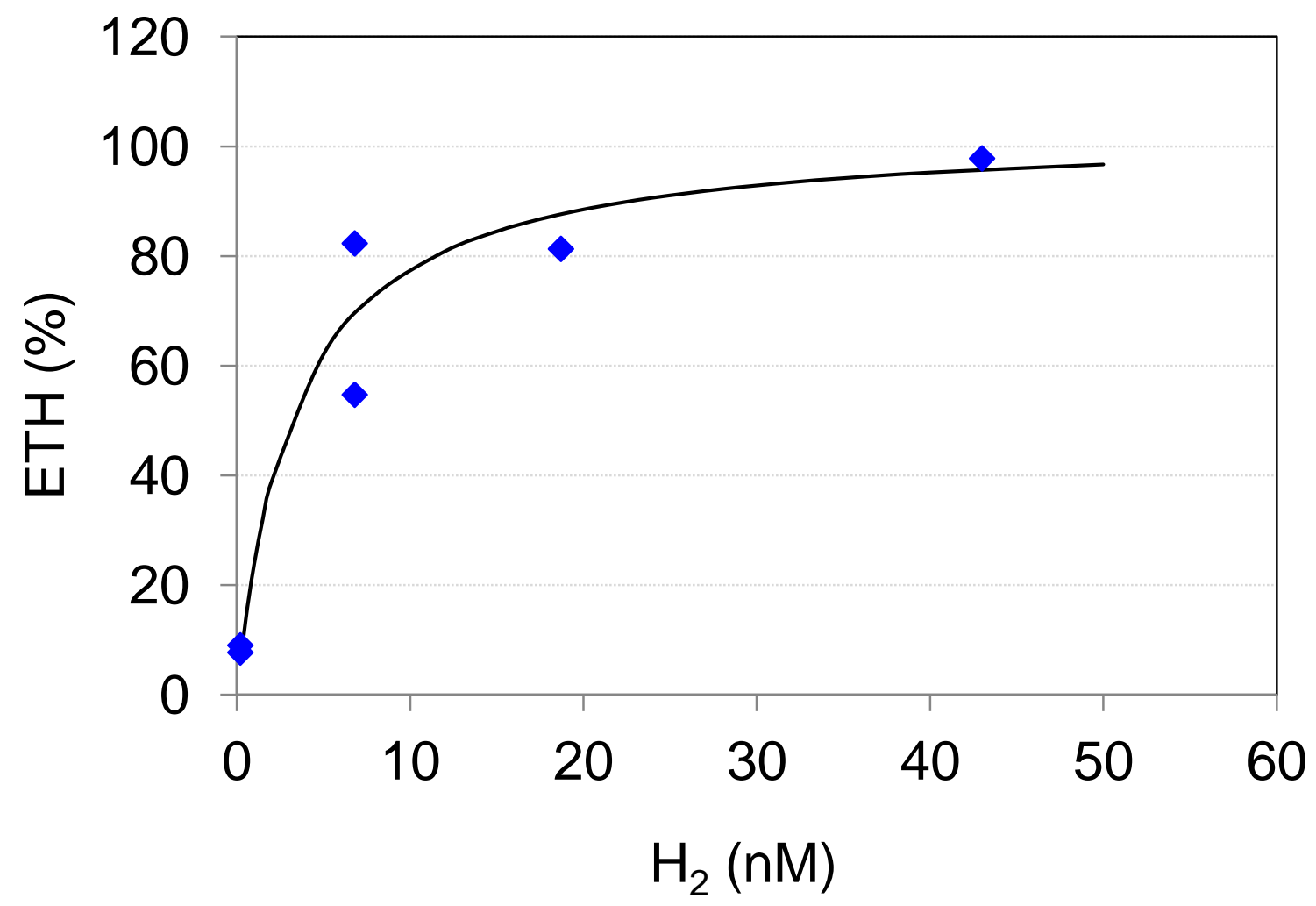

Fig. 4. Extent of transformation of PCE to ethene versus the column effluent $\mathrm{H}_{2}$ concentrations. The solid line represents a Monod type fit where ETH\% $=\mathrm{ETH} \max \% *\left[\mathrm{H}_{2}\right] /\left(\mathrm{K}_{\mathrm{s}}+\left[\mathrm{H}_{2}\right]\right)$. The fit was achieved with an ETH max of $103.1 \%$ and a $\mathrm{K}_{\mathrm{s}}$ of $3.3 \mathrm{nM} \mathrm{H}_{2}$ which represents the $\mathrm{H}_{2}$ concentration when PCE transformation products are 50\% ETH. 
Abstract Art

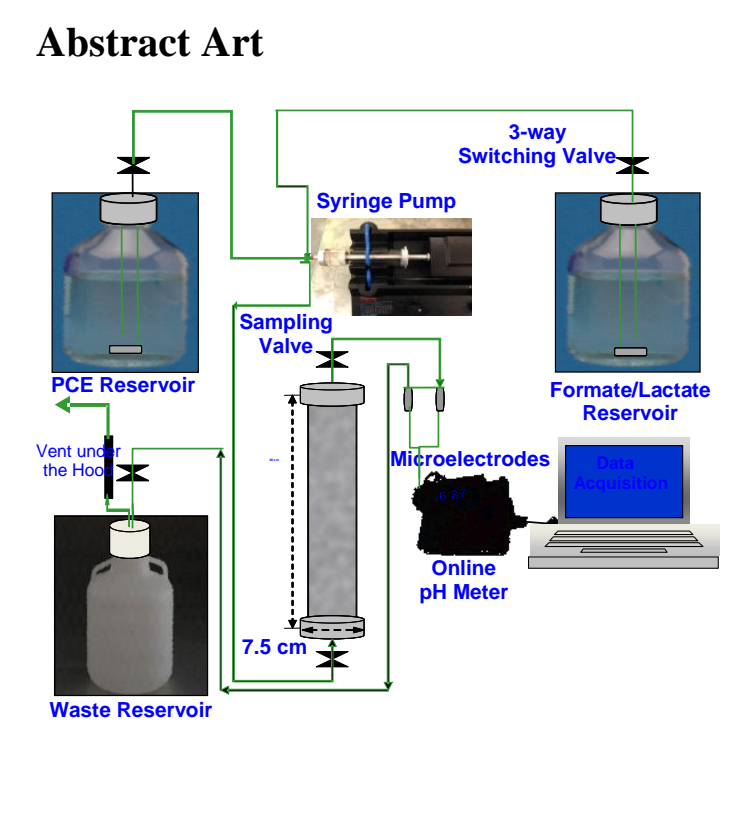

\section{Graphical Abstract}

.

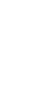
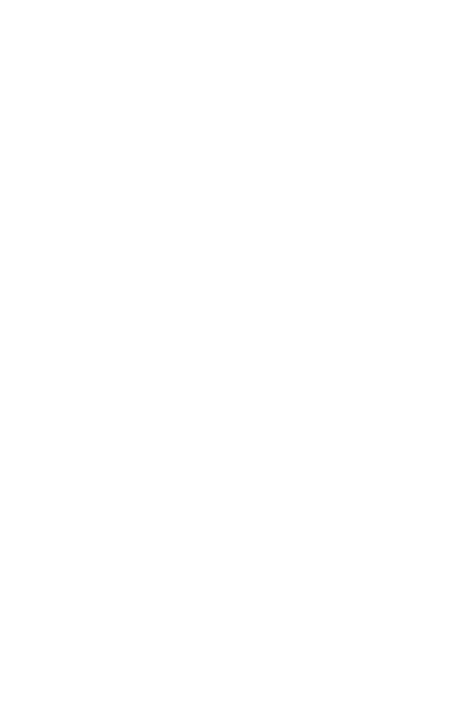

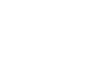
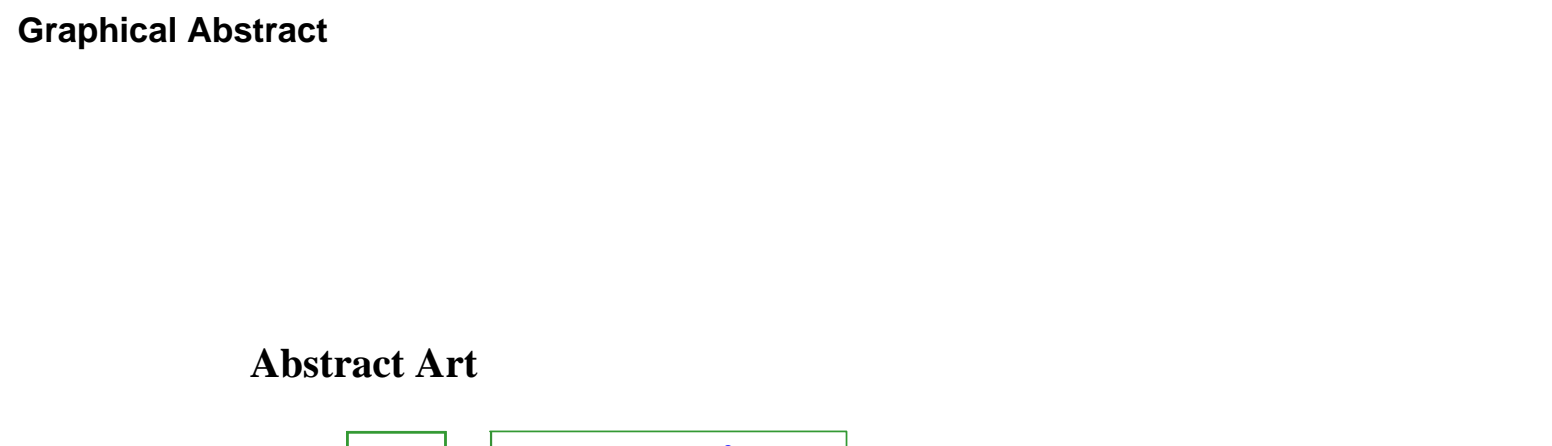

$x^{2}$

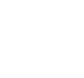

.

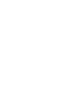

